\title{
Designing Cement Mortars Modified with Cork and Rubber Waste Using Theory of the Experiment
}

\author{
Bernardeta Dębska', Joanna Krasoń1* ${ }^{*}$ Lech Lichołai' \\ 1 Rzeszow University of Technology, Department of Building Engineering, ul. Poznańska 2, 35-959 Rzeszów, \\ Poland \\ * Corresponding author's e-mail: jkras@prz.edu.pl
}

\begin{abstract}
The article concerns the possibility of obtaining modified cement mortars and assessing their selected properties, i.e. bending and compressive strength, volume density of hardened mortars and water absorption. The modification consisted in a partial $(0-50 \%$ vol.) substitution of sand by waste, crushed rubber, and cork. In the mortar design process, the theory of the experiment was used. The central composite design used available in the Statistica software package was response surface. This approach allowed to significantly reduce the number of experiments, reduce costs, and at the same time keep the maximum information about the mortars tested. The conducted research showed that waste materials can be an alternative to natural aggregates in the process of obtaining light mortars.
\end{abstract}

Keywords: rubber waste, cork waste, cement mortars, Design of Experiments (DoE), Response Surface Methodology (RSM)

\section{INTRODUCTION}

Every year, an unlimited amount of waste is created in the world. Due to the increasing scale of this phenomenon, the attempts to recycle waste materials should be made. One of the forms of recycling may be the use of waste in the process of obtaining concrete or mortar. This approach is also important due to the fact that the natural aggregates used for the production of the abovementioned composites are becoming more and more exhausted [1]. The favorable effect of waste on the properties of the composite is expected. However, this is not always the case. Therefore, it is important to determine whether the obtained parameters are still acceptable according to the valid standards and regulations. It is particularly desirable to develop the rubber waste, as it is a very burdensome material for the environment, and its volume on landfill sites is still growing due to the progress of the automotive industry and the growing wealth of societies $[2,3]$. The research on the mortars modified with rubber waste is carried out by many research centers.
Among the applications, the most common statement is that rubber waste reduces the strength parameters of concretes and mortars [4-11]. Nahla Naji Hilal stated that the formation of mechanical features of composites depends on the degree of substitution and the size of waste particles. The modification gives better results when it is possible to obtain greater compatibility of waste and natural aggregates [4]. The negative impact of rubber waste on the strength properties of mortars may also result from the fact that the rubber particles constituting a substitute for fine aggregates increase the air content in the mortars. The volume density of this type of composites ranges from $1150-1852 \mathrm{~kg} / \mathrm{m}^{3}$. As the amount of rubber particles increases, the density of the material decreases due to the change of the aggregate into a material of lower density [12]. The mortars containing rubber are characterized by the reduced water retention capacity, which makes the matrix more brittle [5]. Both the increase in the rubber content and the reduction in the particle size contribute to the increase in the total pore volume [6]. However, G. Xue and M. Cao showed that even at 
$19 \%$ of the content of rubber waste, the resistance of impact mortars is high, and the drying contraction is rational [13]. Moreover, the addition of rubber waste can significantly improve the damping coefficient of the hardened mortar. The mortar modified in this way may still be an alternative to the mortars used in non-structural elements, for obtaining light heat-protective mortars or other building elements, such as partition walls, road barriers, sidewalks etc., for which there is a great demand in the building industry [14]. Low fire resistance disqualifies this type of mortar from the indoor applications, but can be successfully used for external plastering, because they have good thermal and acoustic properties and are impermeable [7]. The mortars containing cork waste can find similar applications in construction. Cork is the bark of the cork-oak tree (Quercus suber L.). It is a natural cellular material, versatile, very light, flexible, dielectric, and impermeable to gases and liquids. It can provide an excellent electri$\mathrm{cal}$, thermal, sound and vibration insulation. The exceptional properties of the cork result from its closed cell structure [15]. The use of foamed cork granules reduces the compressive strength and thermal conductivity of mortars, while increasing their water vapor permeability. The inclusion of cork waste in the mortar results in a reduction in its bulk density. Lightweight mortars obtained in this way are characterized by better thermal and acoustic properties. Thus, these composites can be successfully used as undercoats, filling and leveling layers. They show potential in the applications for shock noise reduction [16]. The low density of the concretes containing cork makes it suitable for repairing buildings, especially those located in seismic areas [17].

Nowadays, all technical innovations that bring profits develop largely on the basis of scientific research. In turn, scientific research is a combination of theory and experiment, with the experiments generating disproportionately high costs compared to the theoretical works. In order to obtain the necessary experimental scientific information as quickly and cheaply as possible, the theory of the experiment should be used. The model of experience described by means of specific processes and real systems from various fields (e.g. technology) can be defined by one universal concept of the so-called test object. In the case of the process of obtaining new materials, it is this material that will be the object of research, and its model will characterize the input (raw materials and technologies) and output quantities (construction material with the desired properties). The correct course of selecting the parameters of the product preparation process requires finding such set of conditions and values of the input quantities that will enable obtaining the most desirable product in terms of its characteristics, i.e. output values. Therefore, the appropriate values should be chosen for those input quantities that have a significant impact on the properties of the product being created, and then describe this relationship by determining the appropriate model, which most often takes the form of an equation. The next step is to find such values of the input quantities that will ensure obtaining the most desirable, easily approximated values of the output quantities. The scheme of a typical research object (RO) appropriate for modern scientific research is presented in Figure 1.

The process of obtaining and evaluating the properties of mortars described in this article was carried out on the basis of the central composite design available in the STATISTICA experience planning module. The research concerned the cement mortars in which $0-50 \%$ vol. aggregates

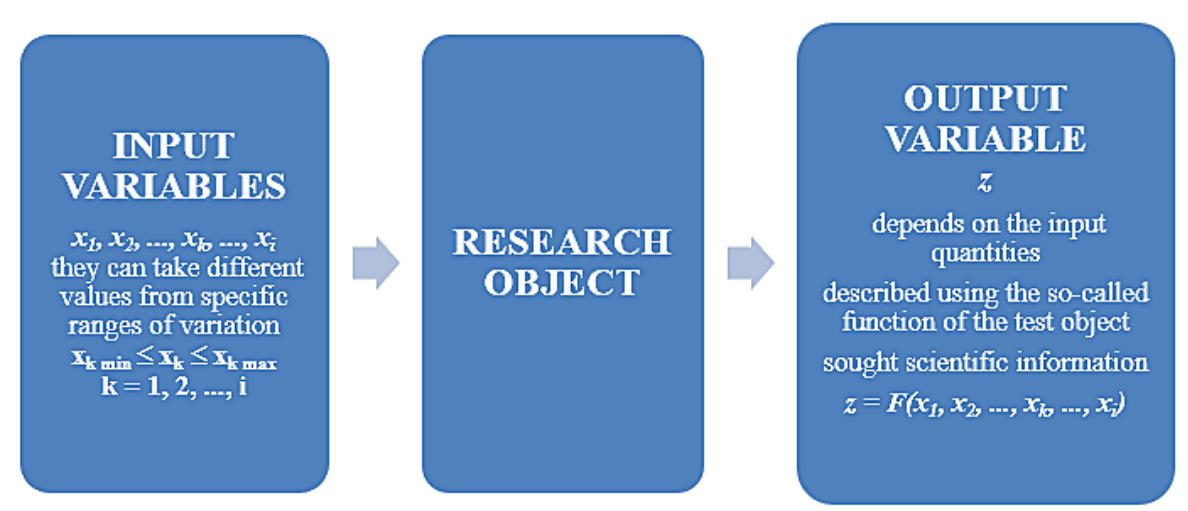

Fig. 1. Scheme of a typical research object (RO) appropriate for modern scientific research 
were replaced with cork waste or rubber waste, respectively. The application of the theory of the experiment allowed for a significant reduction of the number of research samples, and also reduced the costs and time necessary to carry out laboratory tests. At the same time, it enabled obtaining the fullest information on the factors affecting the process of obtaining new mortars modified with the two types of waste.

\section{MATERIALS AND METHODS (EXPERIMENTAL STUDY)}

\section{Design of experiments}

The type of plan that was used in these studies was the compositional central plan. These plans are created by adding in the factor space containing the core a plan of specially arranged additional points (star points) on the coordinate axes and in the center of the plan (center point). When creating the core of the plan, one should design the locations for star points in the admissible area of the experiment. The coordinate value of the star point $\alpha$ and the number of repetitions in the middle of the plan allow to obtain the plans with some additional properties, most often they are rotatable (variance of the predicted value depends only on the distance from the center of the plan) or orthogonal (the values of regression coefficients determined on the basis of the orthogonal plan are independent). The location of plan points on the plan of the designed experiment generated in the STATISTICA software package is shown in Figure 2.

In the case of the mortars described, the input values characterizing the mortar composition were: the water/cement ratio (W/B) and the percentage of waste material in relation to the mass of the aggregate. The output parameters are strength features, bulk density of hardened mortar and absorbability. For the tested mortars it was assumed that the first input variable $\chi_{1}$, which is the water-cement ratio (W/B), will belong to the range from 0.43 to 0.57 , while the second input variable $\chi_{2}$ - the content of waste - will belong to the range from 0 to $50 \%$. The range of variability of input quantities was selected based on the available literature data.

It was assumed that in the experiment plan selected for execution, the stellar arm $\alpha$ will be $\pm \sqrt{2}= \pm 1.414$. Testing of mortar samples was carried out for five intermediate values of the input quantities $\mathrm{x}_{1}$ and $\mathrm{x}_{2}$. In total, 10 series of mortars differing in composition were made, which is presented in Table 1. Each row in this table presents one layout of the plan and describes the parameters of the experiment that needed to be carried out.

The purpose of the numerical analysis of the experiment results was to determine the approximate function of the test object, which approximates the relationship between the output

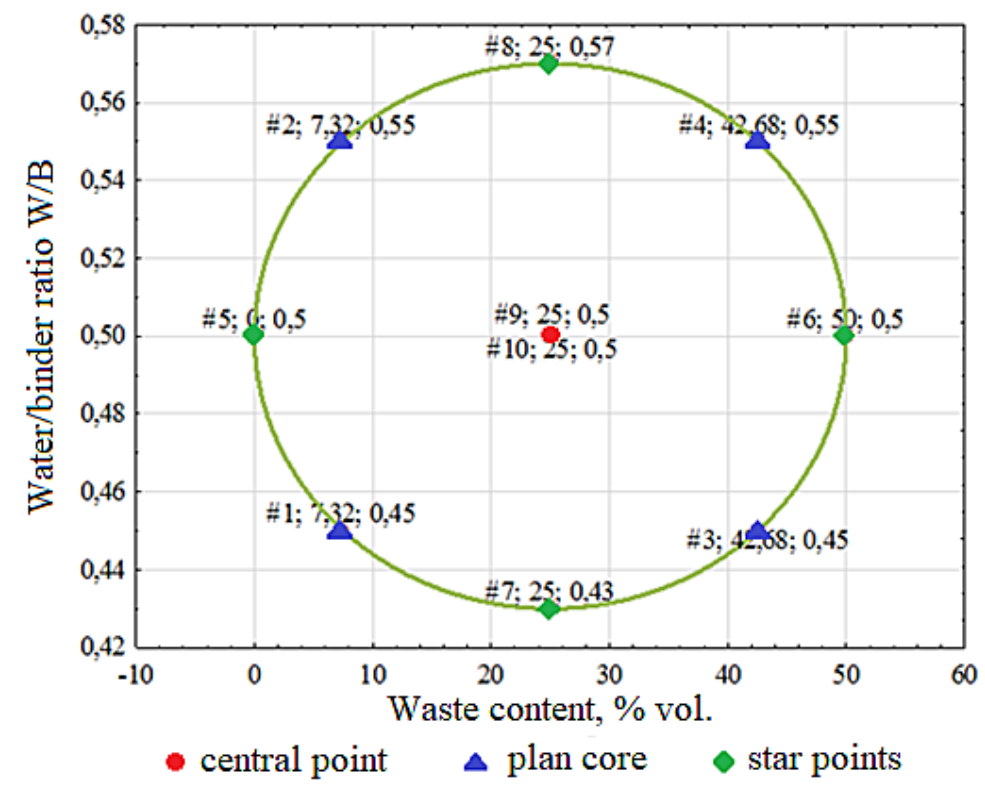

Fig. 2. Distribution of measurement points on the experimental set-up generated as part of research conducted on mortars modified with cork and rubber waste. 
Table 1. Test plan for input variables

\begin{tabular}{|c|c|c|}
\hline Plan point \# & $\begin{array}{c}\text { Waste content, } \\
\text { \% vol. }\end{array}$ & W/B \\
\hline 1 & 7.32 & 0.45 \\
\hline 2 & 7.32 & 0.55 \\
\hline 3 & 42.68 & 0.45 \\
\hline 4 & 42.68 & 0.55 \\
\hline 5 & 0 & 0.50 \\
\hline 6 & 50 & 0.50 \\
\hline 7 & 25 & 0.43 \\
\hline 8 & 25 & 0.57 \\
\hline $10 \mathrm{C}$ & 25 & 0.50 \\
\hline $9 \mathrm{C}$ & 25 & 0.50 \\
\hline
\end{tabular}

quantity and the input quantities. It was assumed that the approximation function will take the form of a second degree polynomial (1). This form of function is suggested by StatSoft experts for the adopted experience plan [18]:

$$
\begin{aligned}
z=b_{0}+b_{1} x_{1} & +b_{2} x_{1}^{2}+b_{3} x_{2}+b_{4} x_{2}^{2}+ \\
& +b_{5} x_{1} x_{2}
\end{aligned}
$$

where: $z$ - the value of the test object function for real variable values,

$\chi_{1}, \chi_{2}-$ real input variables adopted in the research plan:

$\chi_{1}$ - the content of the waste (\%waste),

$\chi_{2}-$ water-cement ratio $(\mathrm{W} / \mathrm{B})$,

$b_{1}$ - equation coefficients calculated for real variables.

Finally, a two-agent polysection quasirotal uniformal design (PS/DS. - P: $\lambda(\not) ; i=2$, with two reruns of the experiment at the central point [19-21] was considered to be optimum.

\section{Materials}

In order to prepare the mortar samples, Class 32.5 R cement of the Polish company Ożarów was used, which, according to the manufacturer's declaration, meets the requirements for the composition and criteria of conformity of common use cements. The chemical composition and selected

Table 2. Chemical composition of cement

\begin{tabular}{|l|c|}
\hline Chemical composition & Value, \% \\
\hline Roasting losses & 2.95 \\
\hline Insoluble parts & 1.36 \\
\hline Sulphate content (as SO3) & 3.17 \\
\hline Chloride content (as Cl-) & 0.08 \\
\hline Alkali content (as Na2Oeq) & 0.78 \\
\hline
\end{tabular}

physical and mechanical properties of cement are listed in Tables 2 and 3, respectively.

The mixing water came from the water supply network. Quartz sand with a bulk density of $1.65 \mathrm{~g} / \mathrm{cm}^{3}$ was used as the aggregate. Cork waste was obtained in the form of granules with grain size: $0.2-2.0 \mathrm{~mm}$ and bulk density at the level of $0.07 \mathrm{~g} / \mathrm{cm}^{3}$. Waste rubber granules with grain size: $0-2.0 \mathrm{~mm}$ and bulk density at the level of $1.65 \mathrm{~g} / \mathrm{cm}^{3}$ were obtained from car tires. Each of the added waste materials was a substitute for aggregates in the amount of $0-50 \%$ by volume. Sand replacement was performed fraction to fraction, based on the grain curves of the aggregates.

\section{Preparation and testing of samples}

Three samples of mortars with dimensions of 40x40x160 mm were prepared for each study and the composition was consistent with the experiment plan presented in Table 1. Each composition consisted of a constant amount of $450 \mathrm{~g}$ of cement and the required amount of water added in accordance with the calculated W/B ratio. The basic sand content is $1350 \mathrm{~g}$. This amount was replaced by rubber or cork waste, respectively, in the proportions consistent with those given in table 1 . The cement was poured into a bowl with water and placed in the machine. The aggregate was dispensed from the mixer's feeder. The programmed mixer adjusted the rotation, total dose and mixing time accordingly. The mortars prepared in this way were placed in demountable steel molds, which were thoroughly cleaned and lubricated. The mortar was laid in two layers, which were compacted with 60 strokes of a shaker. The molds were stored for 24 hours in a laboratory cabinet under the conditions of the required constant temperature and humidity. After 24 hours, the samples were disassembled, signed and placed in a water bath, where they were seasoned for 7 and 28 days, respectively.

The strength tests were carried out in machines adapted for this purpose, equipped with appropriate inserts for bending and compression.

Table 3. Physical and mechanical properties of cement

\begin{tabular}{|l|c|}
\hline \multicolumn{1}{|c|}{ Physical and mechanical properties } & Value \\
\hline Initial setting time, $\mathrm{min}$ & 210 \\
\hline Final setting time, min & 300 \\
\hline Compressive strength (after 28 days), MPa & 45 \\
\hline Density, g/cm ${ }^{3}$ & 3.05 \\
\hline Specific surface area, $\mathrm{cm}^{2} / \mathrm{g}$ & 3300 \\
\hline
\end{tabular}


The samples for determination of bulk density and absorbability were measured and dried to constant mass $\left(m_{s}\right)$. Then they were gradually flooded with water until full immersion. The samples were stored in water until the mass stabilized $\left(m_{n}\right)$.

The volume density of the hardened mortar was calculated according to the formula (2):

$$
\rho=\frac{m_{s}}{V}
$$

where: $\rho$ - bulk density, $\mathrm{g} / \mathrm{cm}^{3}$

$m_{s}$ - the mass of the dry sample, $g$

$V$ - volume of the sample, $\mathrm{cm}^{3}$.

Water absorption was calculated using the formula (3):

$$
N=\frac{m_{n}-m_{s}}{m_{s}} \cdot 100
$$

where: $N$-absorptivity, $\%$

$m_{n}$ - mass of the saturated sample,

$m_{s}-$ the mass of the dry sample.

The determination of absorbability and bulk density was carried out after 28 days of sample maturation.

\section{RESULTS AND DISCUSSION}

The analysis of the test results began from the determination of mean values and standard deviation of the determined parameters, i.e. bending and compression strength, bulk density and absorbability of mortars after 7 and 28 days of maturation, depending on the quantity of waste material added and the value of the assumed water-cement ratio (W/B ), measured when rubber waste $(\mathrm{G})$ and cork $(\mathrm{K})$ were added. These data are presented in Tables 4, 5 and 6.

While analyzing the obtained results of strength parameters, it can be observed that the values of bending strength and compressive strength determined after 7 and 28 days of maturation decrease with the increasing content of both rubber waste $(\mathrm{G})$ and cork $(\mathrm{K})$. In most cases, the highest strength values were obtained for unmodified mortars, the lowest with the highest, or $50 \%$, share of waste material. In tables $4-6$, these values were provided in bold.

While comparing the results obtained in the bending test of standard samples and mortars containing the highest $(50 \%)$ share of waste, it can be observed that after adding the modifier, their value decreased by $43.45 \%$ and by $36.22 \%$ after 7 days of maturation and by $49.94 \%$ and by $42.53 \%$ after 28 days of maturation for rubber and cork waste, respectively. Similarly, after 7 and 28 days of aging, the value of compressive strength decreased by $73.86 \%$ and $65.52 \%$ for rubber waste, and $68.64 \%$ and $73.68 \%$ in the case of waste cork. The second input variable (W/B) also affects the marked strength characteristics, but to a lesser extent than the content of the waste. The bending strength of the mortars containing $7.32 \%$ of waste and with a water-cement ratio of 0.55 for cork waste and is very similar to results obtained for mortars without a modifier. It is similar for rubber waste, except that this waste could be added even in an amount of $25 \%$ (point 7 of the plan of the experiment). The compressive strength obtained for the same values of input variables decreases, but still remains at a quite high level,

Table 4. The results of the bending strength test together with the standard deviation after 7 and 28 days of sample maturation

\begin{tabular}{|c|c|c|c|c|c|c|}
\hline $\begin{array}{c}\text { Plan } \\
\text { point \# }\end{array}$ & W/C & $\begin{array}{c}\text { Waste material } \\
\text { content, volume } \\
\%\end{array}$ & $\begin{array}{c}\text { Flexural strength } \\
\text { after 7 curing } \\
\text { days } \\
\text { G, ff7 } \pm \sigma, \mathrm{MPa}\end{array}$ & $\begin{array}{c}\text { Flexural strength } \\
\text { after 7 curing days } \\
\text { K, ff7 } \pm \sigma, \mathrm{MPa}\end{array}$ & $\begin{array}{c}\text { Flexural strength } \\
\text { after 28 curing days } \\
\mathrm{G}, \mathrm{ff2} \pm \sigma, \mathrm{MPa}\end{array}$ & $\begin{array}{c}\text { Flexural strength after } \\
28 \text { curing days } \\
\mathrm{K}, \mathrm{ff} 28 \pm \sigma, \mathrm{MPa}\end{array}$ \\
\hline 1 & 0.45 & 7.32 & $6.37 \pm 0.14$ & $\mathbf{6 . 4 5 \pm 0 . 1 4}$ & $7.44 \pm 0.09$ & $7.53 \pm 0.57$ \\
\hline 2 & 0.55 & 7.32 & $6.09 \pm 0.18$ & $6.01 \pm 0.28$ & $7.26 \pm 0.28$ & $8.26 \pm 0.19$ \\
\hline 3 & 0.45 & 42.68 & $4.69 \pm 0.14$ & $4.45 \pm 0.47$ & $5.92 \pm 0.10$ & $\mathbf{4 . 9 9 \pm 0 . 1 1}$ \\
\hline 4 & 0.55 & 42.68 & $3.91 \pm 0.40$ & $4.52 \pm 0.18$ & $5.34 \pm 0.23$ & $5.25 \pm 0.31$ \\
\hline 5 & 0.50 & 0 & $\mathbf{6 . 7 2 \pm 0 . 3 4}$ & $6.35 \pm 0.33$ & $\mathbf{8 . 5 3} \pm 0.28$ & $\mathbf{8 . 8 4} \pm 0.63$ \\
\hline 6 & 0.50 & 50 & $\mathbf{3 . 8 0 \pm 0 . 1 9}$ & $\mathbf{4 . 0 5 \pm 0 . 2 1}$ & $\mathbf{4 . 2 7} \pm 0.01$ & $5.08 \pm 0.29$ \\
\hline 7 & 0.43 & 25 & $6.34 \pm 0.24$ & $5.75 \pm 0.43$ & $7.63 \pm 0.13$ & $5.57 \pm 0.31$ \\
\hline 8 & 0.57 & 25 & $4.73 \pm 0.20$ & $4.59 \pm 0.37$ & $6.22 \pm 0.13$ & $6.03 \pm 0.43$ \\
\hline 9 & 0.50 & 25 & $5.40 \pm 0.26$ & $5.79 \pm 0.10$ & $6.98 \pm 0.29$ & $6.82 \pm 0.28$ \\
\hline 10 & 0.50 & 25 & $5.46 \pm 0.21$ & $5.55 \pm 0.37$ & $7.03 \pm 0.15$ & $6.55 \pm 0.08$ \\
\hline
\end{tabular}


Table 5. Results of compressive strength test with standard deviation after 7 and 28 days of sample maturation

\begin{tabular}{|c|c|c|c|c|c|c|}
\hline $\begin{array}{c}\text { Plan } \\
\text { point \# }\end{array}$ & W/C & $\begin{array}{c}\text { Waste material } \\
\text { content, } \\
\text { vol. \% }\end{array}$ & $\begin{array}{c}\text { Compressive } \\
\text { strength after 7 } \\
\text { curing days } \\
\mathrm{G}_{\mathrm{fc} 7} \pm \sigma, \mathrm{MPa}\end{array}$ & $\begin{array}{c}\text { Compressive } \\
\text { strength after 7 } \\
\text { curing days } \\
\mathrm{K}_{\mathrm{c} 7} \pm \sigma, \mathrm{MPa}\end{array}$ & $\begin{array}{c}\text { Compressive strength } \\
\text { after 28 curing days } \\
\mathrm{G}_{\mathrm{c} 28} \pm \sigma, \mathrm{MPa}\end{array}$ & $\begin{array}{c}\text { Compressive strength } \\
\text { after 28 curing days } \\
\mathrm{K} \mathrm{f}_{\mathrm{c} 28} \pm \sigma, \mathrm{MPa}\end{array}$ \\
\hline 1 & 0.45 & 7.32 & $26.88 \pm 3.09$ & $26.98 \pm 1.03$ & $24.58 \pm 2.29$ & $30.28 \pm 1.88$ \\
\hline 2 & 0.55 & 7.32 & $23.23 \pm 0.58$ & $20.88 \pm 0.42$ & $27.08 \pm 1.59$ & $23.38 \pm 1.65$ \\
\hline 3 & 0.45 & 42.68 & $13.83 \pm 2.59$ & $10.75 \pm 0.65$ & $16.65 \pm 1.87$ & $9.48 \pm 1.07$ \\
\hline 4 & 0.55 & 42.68 & $10.27 \pm 0.56$ & $\mathbf{8 . 7 0 \pm 0 . 4 6}$ & $12.35 \pm 0.93$ & $10.08 \pm 0.45$ \\
\hline 5 & 0.50 & 0 & $\mathbf{3 3 . 7 8 \pm 2 . 1 8}$ & $\mathbf{2 8 . 7 0 \pm 0 . 8 0}$ & $\mathbf{3 4 . 4 5 \pm 1 . 4 9}$ & $\mathbf{3 5 . 1 5} \pm 1.30$ \\
\hline 6 & 0.50 & 50 & $\mathbf{8 . 8 3} \pm \mathbf{0 . 9 6}$ & $9.00 \pm 0.64$ & $\mathbf{1 1 . 8 8 \pm 0 . 5 6}$ & $\mathbf{9 . 2 5 \pm 0 . 3 7}$ \\
\hline 7 & 0.43 & 25 & $19.95 \pm 1.34$ & $16.70 \pm 1.16$ & $22.83 \pm 1.75$ & $12.78 \pm 0.26$ \\
\hline 8 & 0.57 & 25 & $11.98 \pm 1.77$ & $12.27 \pm 0.92$ & $17.85 \pm 0.38$ & $14.35 \pm 1.28$ \\
\hline 9 & 0.50 & 25 & $13.28 \pm 3.84$ & $14.98 \pm 0.63$ & $19.18 \pm 1.26$ & $16.10 \pm 0.32$ \\
\hline 10 & 0.50 & 25 & $16.78 \pm 1.12$ & $12.98 \pm 0.71$ & $23.20 \pm 1.46$ & $15.45 \pm 0.52$ \\
\hline
\end{tabular}

above $20 \mathrm{MPa}$. The mortars with such parameters can be successfully used as undercoats, floors, or screeds. The cork-modified mortars are characterized by slightly higher bending strength after 7 and 28 days of maturation compared to the rubber-containing mortars. In turn, the higher values of compressive strength determined after 28 days of maturing are characterized by the mortar samples containing $50 \%$ of rubber waste.

The lack of statistically significant differences among the strength parameters, absorbability and bulk density of mortars with the addition of rubber and cork waste was confirmed by the Student's ttest for groups (T-test for Independent Samples by Variables) available in the STATISTICA software package. The sample results of the Student's t-test are shown in Table 7. The results of this test can also be illustrated graphically, as shown in the frame-mustache graphs (Figures 3 and 4).

The differences in the volume density of the hardened mortar (Figure 4) in the case of the addition of cork waste are more visible and result from the use of waste, which is much lighter than sand. The research of other authors [15] confirmed that the mortars containing this type of waste also have better thermal insulation, which translates into the possibility of their application, e.g. as light heat-protective plasters.

In the next step, i.e. the analysis of the results obtained using the central compositional plan, the significance of the influence of the input quantities on the output quantities was checked. For this purpose, F Fisher-Snedecor's F test for different sizes was used, which is also a test for equality of averages. At the significance level of 0.05 , for the parameters: content of waste and W/B - ratio of water to binder (cement), it can be confirmed that there is a significant impact on the output quantities. This is evidenced by the calculated values of parameter $p$, which are less than 0.05 . On this basis, the statistical hypothesis on equality of averages can also be rejected, which is tantamount

Table 6. Results of volumetric density and water absorption tests with standard deviation

\begin{tabular}{|l|l|l|l|l|l|l|}
\hline $\begin{array}{l}\text { Plan point } \\
\#\end{array}$ & W/C & $\begin{array}{l}\text { Waste material } \\
\text { Content, vol. } \%\end{array}$ & $\begin{array}{l}\text { Bulk density } \\
\mathrm{G}, \rho \pm \sigma, \frac{g}{\mathrm{~cm}^{3}}\end{array}$ & $\mathrm{~K}, \rho \pm \sigma, \frac{\mathrm{cm}}{3}$ & $\begin{array}{l}\text { Absorptivity } \\
\mathrm{G}, \mathrm{N} \pm \sigma, \%\end{array}$ & $\mathrm{~K}, \mathrm{~N} \pm \sigma, \%$ \\
\hline 1 & 0.45 & 7.32 & $2.08 \pm 0.05$ & $2.07 \pm 0.02$ & $7.39 \pm 0.11$ & $7.67 \pm 0.03$ \\
\hline 2 & 0.55 & 7.32 & $2.06 \pm 0.02$ & $2.02 \pm 0.04$ & $8.85 \pm 0.34$ & $9.58 \pm 0.06$ \\
\hline 3 & 0.45 & 42.68 & $1.76 \pm 0.01$ & $1.69 \pm 0.04$ & $9.52 \pm 0.11$ & $12.18 \pm 0.56$ \\
\hline 4 & 0.55 & 42.68 & $1.76 \pm 0.02$ & $1.62 \pm 0.02$ & $11.89 \pm 0.15$ & $13.43 \pm 0.08$ \\
\hline 5 & 0.50 & 0 & $2.11 \pm 0.03$ & $2.16 \pm 0.04$ & $7.96 \pm 0.10$ & $7.86 \pm 0.05$ \\
\hline 6 & 0.50 & 50 & $1.66 \pm 0.04$ & $1.49 \pm 0.03$ & $11.23 \pm 0.16$ & $13.38 \pm 0.21$ \\
\hline 7 & 0.43 & 25 & $2.03 \pm 0.03$ & $1.89 \pm 0.06$ & $7.36 \pm 0.05$ & $9.37 \pm 0.14$ \\
\hline 8 & 0.57 & 25 & $1.94 \pm 0.04$ & $1.81 \pm 0.05$ & $10.07 \pm 0.12$ & $11.77 \pm 0.15$ \\
\hline 9 & 0.50 & 25 & $2.00 \pm 0.04$ & $1.87 \pm 0.01$ & $9.05 \pm 0.39$ & $10.40 \pm 0.11$ \\
\hline 10 & 0.50 & 25 & $2.01 \pm 0.02$ & $1.86 \pm 0.03$ & $8.72 \pm 0.17$ & $10.21 \pm 0.07$ \\
\hline
\end{tabular}


Table 7. Student's t-test results on equality of means for compressive strength determined after 28 days of maturation and for the bulk density determined after 28 days of maturation

\begin{tabular}{|l|c|c|c|c|c|}
\hline \multirow{2}{*}{ Group 1 vs. Group 2 } & \multicolumn{4}{|c|}{ Notest for Independent Samples } \\
\cline { 2 - 5 } & $\begin{array}{c}\text { Mean } \\
\text { Group 1 }\end{array}$ & $\begin{array}{c}\text { Mean } \\
\text { Group 2 }\end{array}$ & t-value & df & $\mathrm{p}$ \\
\hline $\begin{array}{l}\text { Compressive strength (K) 28 day, MPa vs. } \\
\text { Compressive strength (G) 28 day, MPa }\end{array}$ & 17.62750 & 21.00250 & -0.938424 & 18 & 0.360449 \\
\hline $\begin{array}{l}\text { Volumetric density (G), g/cm } 3 \text { vs. } \\
\text { Volumetric density (K), g/cm }\end{array}$ & 1.940481 & 1.851329 & 1.091095 & 18 & 0.289621 \\
\hline
\end{tabular}

to stating that the composition of the raw material mixture significantly differentiates the properties of the samples. With the Brown-Forsythe test, the hypothesis of homogeneity of variance was confirmed, which enabled the process of searching for functions describing the research object. It was assumed that the approximation function will take the form of a second degree polynomial (1). The summary of the results of the experiment carried out on the basis of the compositional central plan can be presented in the form of spatial and contour plots of the response surface. For each of the output variables and for each type of modifier an appropriate response area was determined. The exemplary spatial graphs of the response surface for flexural strength, measured after 28 days of curing, are presented in Figure 5. Similar graphs were also generated for variable absorbability and bulk density (Figures 6 and 7).

The graphs presented in Figures 5 and 6 show the negative impact of waste materials on the mortar strength. In the case of rubber waste, the maximum is also shifted towards the lower W/B values (Fig. 5a). However, the same graphs confirm that with the addition of up to $25 \%$ of the rubber waste, the strength values very similar to those recorded for the reference samples (without the modifier) can be obtained.

While analyzing the data contained in Table 6 and the graphs presented in Figure 7, it can be concluded that both the share of waste and the ratio $\mathrm{W} / \mathrm{B}$ affect the absorbability of mortars. The desirable lowest values of this feature can be achieved in the case of the mortars produced without waste material and at the lowest W/B ratio. The mortars containing cork are characterized by a slightly higher water absorption compared to the mortars in the production of which rubber waste was used. High absorbability values of the modified mortars may result from poorer workability of the mix and increased porosity of these mortars, as both rubber and cork are materials that have low absorbability. Their high content in the mortar causes difficulties with compaction. This creates air voids in which water penetrates, increasing the absorbability of the resulting composite.

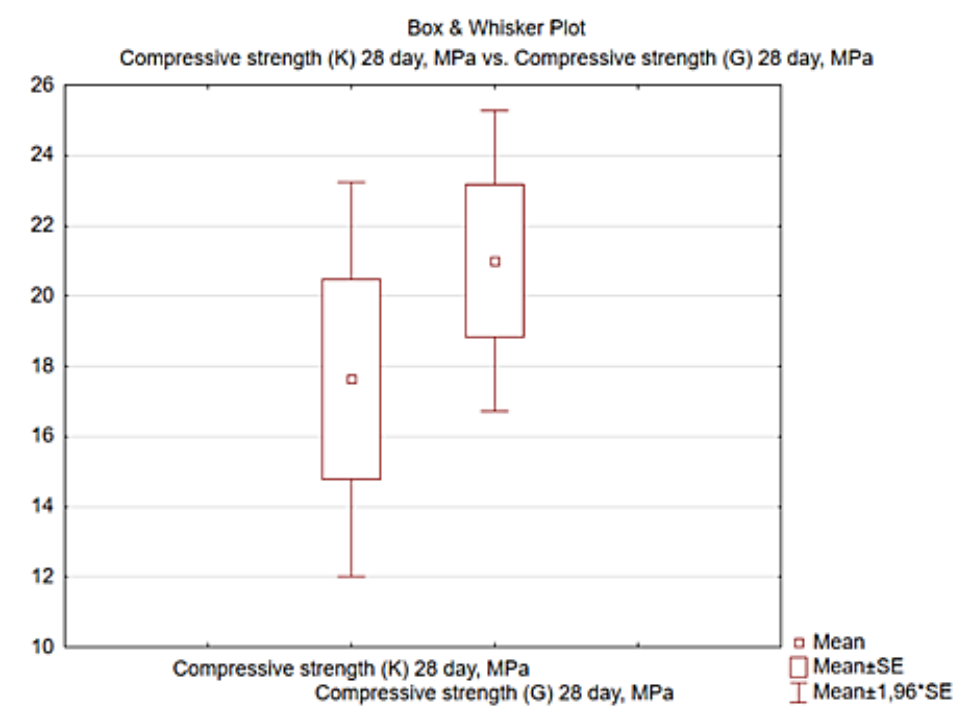

Fig. 3. Frame-whisks chart for medium compressive strength determined after 28 days of maturation for samples containing rubber and cork waste 
Box \& Whisker Plot

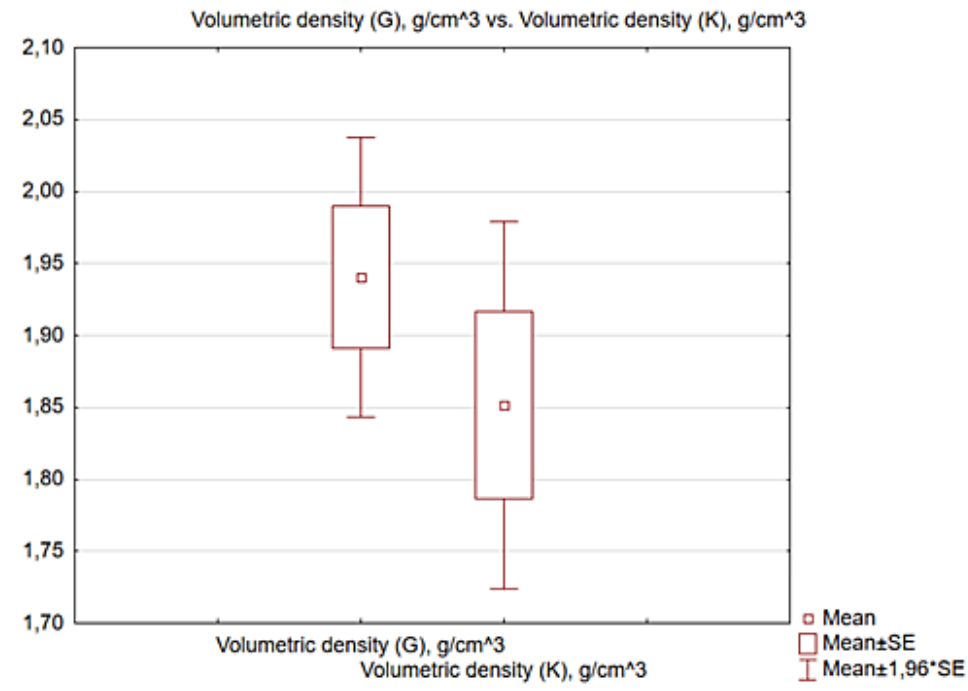

Fig. 4. Frame-whisker chart for medium bulk densities after 28 days of maturation for samples containing rubber and cork waste

a)

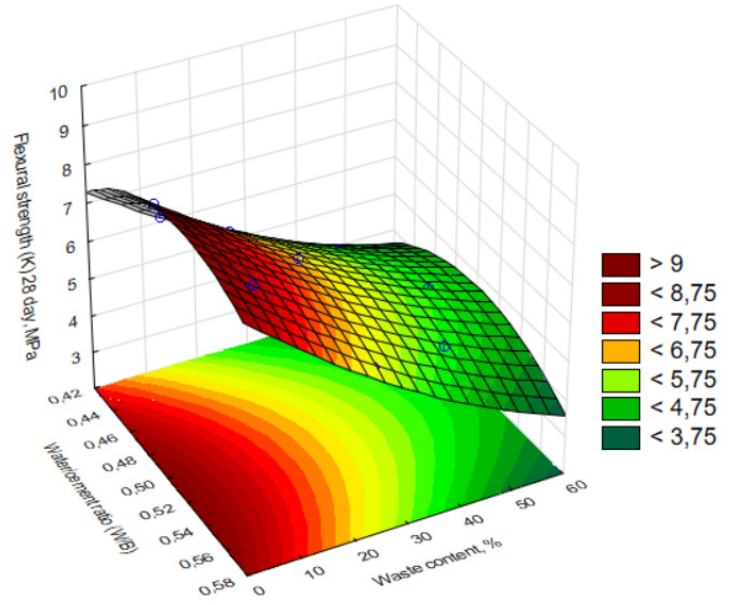

b)

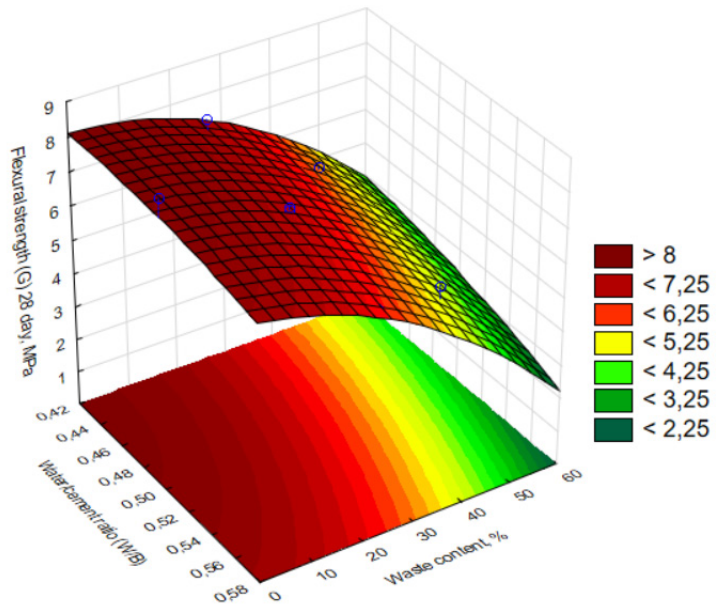

Fig. 5. Spatial plot of the response surface for bending strength after 28 days of ripening of modified mortars (a) of rubber, (b) cork

a)

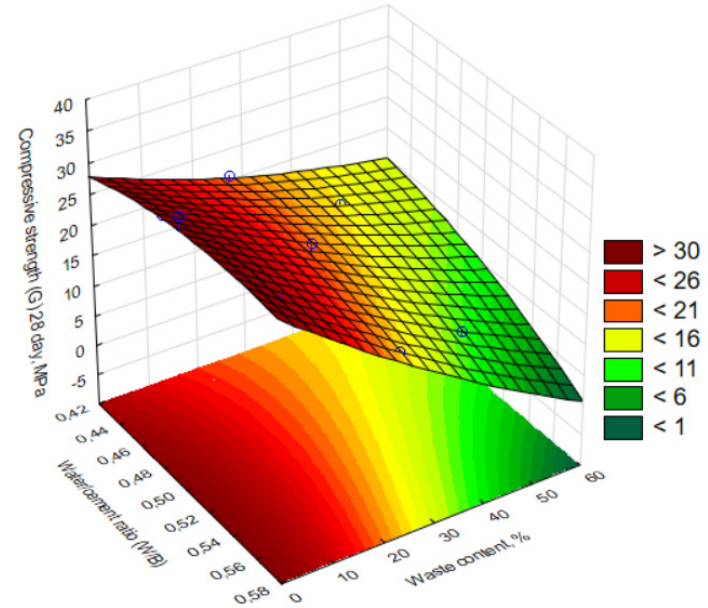

b)



Fig. 6. Spatial plot of response surface for compressive strength after 28 days of ripening of modified mortars (a) of rubber, (b) cork 
a)

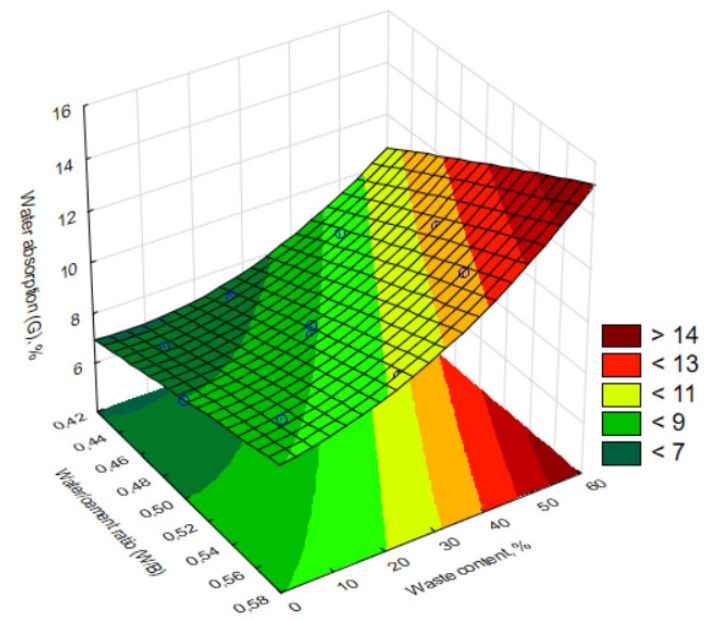

b)

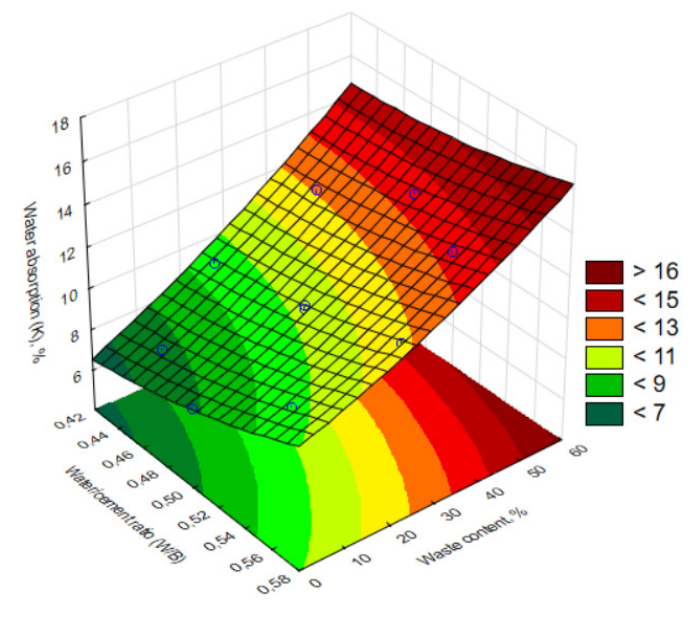

Fig. 7. Spatial chart of the response surface for absorbability of mortars modified with waste (a) rubber, (b) cork

a)



b)

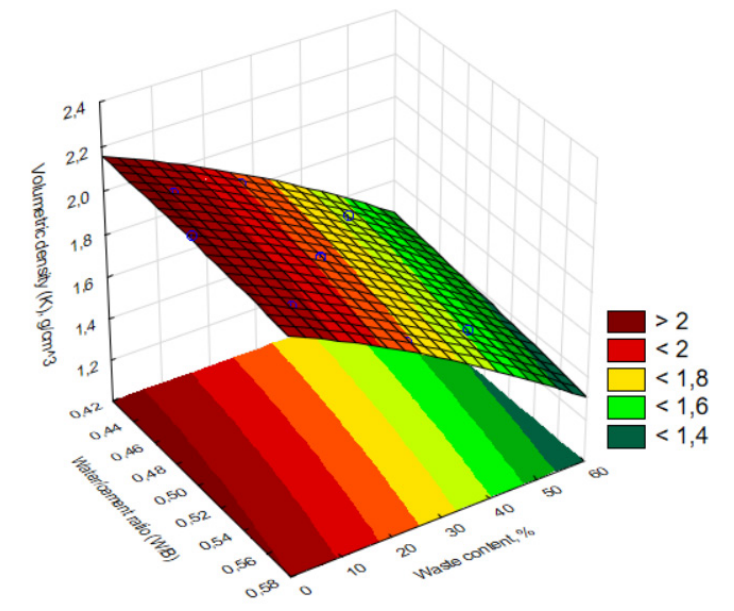

Fig. 8. Spatial plot of response area for bulk density of hardened mortar modified with waste (a) rubber, (b) cork

Both graphs shown in Figure 8 confirm that with the increase in the content of waste material, the bulk density decreases. The maximum response surface is also shifted towards the lower values of the water-cement ratio. In this case, it is easier to thicken the mortar, but a part of the water that will not take part in the hydration process remains in the mortar, which in turn may increase the porosity of the composite structure.

\section{CONCLUSIONS}

In the conducted research, the project of planning the experiment using the method involving optimization of the surface of the response were implemented in order to investigate the effect of modifying the composition of the composite on selected mortar properties. The analysis of the obtained results allowed drawing the following conclusions:

- The value of bending strength and compressive strength determined after 7 and 28 days of maturation decreases with the increasing content of both rubber waste $(\mathrm{G})$ and cork $(\mathrm{K})$. In most cases, the highest strength values were obtained for unmodified mortars, the lowest with the highest, or $50 \%$, share of waste material.

- The use of $7.32 \%$ cork waste and even $25 \%$ rubber waste allows to obtain satisfactory bending strength results, similar to those obtained for unmodified samples.

- Compressive strength decreases, but still remains at a quite high level, above $20 \mathrm{MPa}$.

- High absorbability values of the modified mortars may result from poorer workability of the mix and increased porosity of these mortars, 
as both rubber and cork are materials that have low absorbability.

- The mortars modified with cork and rubber waste can be successfully used in such solutions as: light heat-protective plasters, undercoats, or partition walls.

\section{REFERENCES}

1. Rashad A.M. 2016. A comprehensive overview about recycling rubber as fine aggregate replacement in traditional cementitious materials. International Journal of Sustainable Built Environment, 5(1), 46-82.

2. Song W-J., Qiao W-G., Yang X-X., Lin D-G., Li Y-Z. 2018. Mechanical properties and constitutive equations of crumb rubber mortars. Construction and Building Materials 17, 660-669.

3. Dębska B., Lichołai L., Miąsik P. 2019. Assessment of the Applicability of Sustainable Epoxy Composites Containing Waste Rubber Aggregates in Buildings. Buildings, 9(2), 31.

4. Hilal N.N. 2017. Hardened properties of self-compacting concrete with different crumb rubber size and content. International Journal of Sustainable Built Environment, 6, 191-206.

5. Pczieczek A., Schackow A., Effting C., Flores Dias T., Ribeiro Gomes I. 2017. Properties of mortars containing tire rubber waste and expanded polystyrene (EPS). Journal of Urban and Environmental Engineering, 11(2), 219-225.

6. Yu Y., Zhu H. 2016. Influence of Rubber Size on Properties of Crumb Rubber Mortars. Materials 9, 527. https://doi.org/10.3390/ma9070527.

7. Faizah R., Priyosulistyo H., Aminullah A. 2019. An Investigation on Mechanical Properties and Damping Behaviour of Hardened Mortar with Rubber Tire Crumbs (RTC). MATEC Web of Conferences, 258, 05002. https://doi.org/10.1051/matecconf/20192 $2585805002,4$.

8. Sotiriadis K., Tupý M., Žižková N., Petránek V. 2014. Acid Attack on Cement Mortars Modified with Rubber Aggregates and EVA Polymer Binder. Civil and Environmental Engineering, 8(6). waset. org/Publication/9998405.

9. Jusoh M.A., Abdullah S.R., Adnan S.H. 2018. Strength of mortar containing rubber tire particle. IOP Conference Series: Earth and Environmental Science 140, 012144. https://doi.org/10.1088/1 $755-1315 / 140 / 1 / 012144$.
10. Etli S., Cemalgil S., Onat O. 2018. Mid-Temperature Thermal Effects on Properties of Mortar Produced with Waste Rubber as Fine Aggregate. International Journal of Pure and Applied Sciences and Technology, 4(1): 10-22.

11. Bustamante A., Dablo G.M., Sia R., Arazo R. 2015. Physical and mechanical properties of composite brick from cement mortar, fly ash and rubber crumbs. 4(10). http://www.ijret.org.

12. Aciu C. 2013. Possibilities of Recycling Rubber Waste in the Composition of Mortars. ProEnvironment, 6, 479-483. http://journals.usamvcluj.ro/index.php/promediu.

13. Xue G., Cao M-L. 2017. Effect of Modified Rubber Particles Mixing Amount on Properties of Cement Mortar. Advances in Civil Engineering, 8643839. https://doi.org/10.1155/2017/8643839.

14. Asutkar P., Shinde S.B., Patel R. 2017. Study on the behaviour of rubber aggregates concrete beams using analytical approach. Engineering Science and Technology, 20, 151-159.

15. Brás A., Leal M., Faria P. 2013. Cement-cork mortars for thermal bridges correction. Comparison with cement-EPS mortars performance. Construction and Building Materials, 49, 315-327.

16. Gil L. 2015. New Cork-Based Materials and Applications. Materials, 8, 625-637.

17. Parra C., Sánchez E. M., Miñano I., Benito F., Hidalgo P. 2019. Recycled Plastic and Cork Waste for Structural Lightweight Concrete Production. Sustainability, 11, 1876. https://doi.org/10.3390/ su11071876.

18. Polański Z., Pietraszek J. 2007. Komputerowe wspomaganie planowania i analizy statystycznej doświadczalnych badań innowacyjnych, StatSoft, Rzeszów (in Polish).

19. Dębska B.J., Dobrowolski L., Dębska B. 2018. Experiment-design methods in innovative polymer material planning. Journal of Applied Polymer Science 135(46), e46761. https://doi.org/10.1002/ app. 46761 .

20. Lichołai L., Dębska B., Krasoń J. 2019. Assessment of the applicability of a phase change material in horizontal building partitions. IOP Conference Series: Earth Environmental Science, 214 e012042. https://doi.org/10.1088/1755-1315/214/1/012042.

21. Musiał M. 2018. Analysis of the impact of selected factors on the effectiveness of using PCM in mobile window insulation, E3S Web Conferences 49, e00073. https://doi.org/10.1051/e3sconf/20184900073. 